\title{
Ensino de Astronomia para pessoas com deficiência visual: Um levantamento sobre a produção bibliográfica em congressos no Brasil
}

\author{
Astronomy Teaching for people with visual disabilities: A survey on bibliographic production in \\ congresses in Brazil
}

Enseñanza de Astronomía para personas con discapacidad visual: Una encuesta sobre producción bibliográfica en congresos de Brasil

Recebido: 02/04/2021 | Revisado: 11/04/2021 | Aceito: 16/06/2021 | Publicado: 28/06/2021

\author{
Andre Lucas Matthaeus Santos \\ ORCID: https://orcid.org/0000-0002-0332-9683 \\ Instituto Federal de Educação, Ciência e Tecnologia de Minas Gerais, Brasil \\ E-mail: as0645922@gmail.com \\ Arilson Paganotti \\ ORCID: https://orcid.org/0000-0001-5338-9898 \\ Instituto Federal de Educação, Ciência e Tecnologia de Minas Gerais, Brasil \\ E-mail: arilson.paganotti@ifmg.edu.br \\ Ana Rachel Carvalho Leão \\ ORCID: https://orcid.org/0000-0002-9302-4145 \\ Instituto Federal de Educação, Ciência e Tecnologia de Minas Gerais, Brasil \\ E-mail: ana.leao@ifmg.edu.br
}

\begin{abstract}
Resumo
Uma das ciências mais antigas, a Astronomia sempre instigou a curiosidade do ser humano. No entanto, ela não vem sendo ensinada dentro das escolas da maneira como deveria ser. Além disso, com o surgimento da Lei Brasileira de Inclusão ${ }^{1}$, o número de alunos com deficiência visual vem aumentando nas escolas. Porém, os educadores, em grande parte, não são preparados para trabalhar Astronomia na sala de aula, muito menos com alunos com deficiência visual. Diante dessa realidade, foi proposto neste trabalho, uma revisão bibliográfica, para investigar as tendências da pesquisa brasileira em Ensino de Astronomia para pessoas com deficiência visual, além de auxiliar educadores em sua busca por fontes para trabalhar este tópico com seus alunos. A pesquisa foi realizada junto aos anais de seis congressos brasileiros. A análise dos dados foi feita com base na Análise de Conteúdo por categorização a partir de três descritores. Algumas conclusões obtidas mostram que o número de pesquisas na área, apesar de serem poucas, vem aumentando nos últimos anos. Além disso, pesquisas vêm sendo feitas não somente no ambiente escolar, mas também fora das escolas. Notou-se também que a maioria das publicações envolvem fabricação e uso de matérias táteis, por serem mais fáceis e práticos de trabalhar, além da possibilidade de serem fabricados com materiais de baixo custo.
\end{abstract}

Palavras-chave: Astronomia; Deficiência visual; Cego; Ensino.

\begin{abstract}
One of the oldest sciences, Astronomy has always instigated the curiosity of the human being. However, it has not been taught within schools the way it should be. In addition, with the emergence of the Brazilian Inclusion Law, the number of students with visual impairments has been increasing in schools. However, educators, for the most part, are not prepared to work astronomy in the classroom, much less with visually impaired students. In view of this reality, a bibliographic review was proposed in this work, to investigate trends in Brazilian research in Astronomy Teaching for visually impaired people, in addition to assisting educators in their search for sources to work on this topic with their students. The research was carried out in the annals of six Brazilian congresses. Data analysis was performed based on Content Analysis by categorization based on three descriptors. Some conclusions obtained show that the number of researches in the area, although few, has been increasing in recent years. Besides that, research has been carried out not only in the school environment, but also outside schools. It was also noted that most publications involve the manufacture and use of tactile materials, as they are easier and more practical to work with, besides the possibility of being manufactured with low-cost materials.
\end{abstract}

Keywords: Astronomy; Visual impairment; Blind; Teaching.

\footnotetext{
${ }^{1}$ Lei $\mathrm{N}^{0} 13.146$ de 6 de julho de 2015.
} 


\begin{abstract}
Resumen
Una de las ciencias más antiguas, la Astronomía siempre ha instigado la curiosidad del ser humano. Sin embargo, no se ha enseñado en las escuelas de la manera que debería ser. Además, con la aparición de la Ley de Inclusión brasileña, el número de estudiantes con discapacidad visual ha aumentado en las escuelas. Sin embargo, los educadores, en su mayor parte, no están preparados para trabajar la astronomía en el aula, y mucho menos con estudiantes con discapacidad visual. Ante esta realidad, se propuso una revisión bibliográfica en este trabajo, para investigar las tendencias de la investigación brasileña en la Enseñanza de la Astronomía para personas con discapacidad visual, además de ayudar a los educadores en la búsqueda de fuentes para trabajar este tema con sus estudiantes. La investigación se llevó a cabo en los anales de seis congresos brasileños. El análisis de datos se realizó con base en el Análisis de Contenido por categorización basada en tres descriptores. Algunas conclusiones obtenidas muestran que el número de investigaciones en la zona, aunque pocas, ha ido aumentando en los últimos años. Además, la investigación se ha llevado a cabo no solo en el entorno escolar, sino también fuera de las escuelas. También se señaló que la mayoría de publicaciones implican la fabricación y uso de materiales táctiles, ya que son más fáciles y prácticos de trabajar, además de la posibilidad de ser fabricados con materiales de bajo costo.
\end{abstract}

Palabras clave: Astronomía; Discapacidad visual; Ciego; Ensenãnza.

\title{
1. Introdução
}

A Astronomia é uma das ciências mais antigas da humanidade. Desde os primórdios da civilização, olha-se para o céu com admiração e curiosidade. Além disso, a Astronomia desde o início foi muito importante, pela necessidade do ser humano em se orientar, além de seu uso para a agricultura e para medir a passagem do tempo. Até mesmo para fins religiosos, pois acreditava-se que os astros eram deuses do céu e tinham o poder sobre a colheita, a chuva e sobre a vida e a morte.

De acordo com Soler e Leite (2012):

a Astronomia possui uma relevância sócio-histórico-cultural significativa no decorrer da história humana, pois o seu desenvolvimento proporcionou várias contribuições para a evolução das civilizações, como a oportunidade de registrar e organizar o tempo, aprimorar a agricultura e a orientação necessária para as grandes viagens, como na época das grandes navegações (Soler \& Leite, 2012, p. 3).

Outros pesquisadores afirmam que as principais consequências que o desenvolvimento da Astronomia veio a trazer no decorrer dos séculos, foi a possibilidade de se realizar registros da passagem do tempo (Oliveira, Voelzke, \& Amaral, 2007, Faria, \& Voelzke, 2008, Longhini, 2009) e o estabelecimento de vínculos entre determinadas datas de importância política, social, religiosa e cultural, a fenômenos celestes (Fares et al., 2004, Faria, \& Voelzke, 2008).

Pelo fato de a Astronomia ser um tópico importante, está presente nos Parâmetros Curriculares Nacionais (PCN), tanto do Ensino Fundamental quanto do Ensino Médio e traz como tema estruturador Terra, Universo e Vida. Tal tema propõe que tópicos relacionados à Astronomia, como Terra e Sistema Solar, o Universo e sua origem, sejam abordados dentro da sala de aula.

De acordo com o PCN+ (Brasil, 2007), é fundamental que o jovem compreenda a natureza cosmológica, de forma a refletir sobre sua presença na história do Universo.

Porém, o Ensino de Astronomia dentro das escolas vem de encontro a outro tema bastante debatido no âmbito educacional: A Lei Brasileira de Inclusão da Pessoa com Deficiência (Lei N ${ }^{0}$ 13.146), de 6 de julho de 2015 (Brasil, 2015), destinada a assegurar e a promover, em condições de igualdade, o exercício dos direitos e das liberdades fundamentais da pessoa com deficiência, visando à sua inclusão social e cidadania. Outro documento que trata desse assunto, a Declaração de Salamanca (Unesco, 1994), diz que “aqueles com necessidades educacionais especiais devem ter acesso à escola regular, que deverá acomodá-los dentro de uma Pedagogia capaz de satisfazer a tais necessidades." Todavia, o sistema de ensino no Brasil apresenta problemas, e grande parte dos professores, durante sua formação, não são preparados na perspectiva da Educação Inclusiva, como afirma Romero e Souza (2008): “quando falamos sobre inclusão de deficientes nas escolas regulares, é comum ouvirmos as queixas dos docentes, pois estes não se sentem preparados para trabalhar com esse público, 
acreditam que é necessário ter formação especialista (Romero \& Sousa, 2008, p.1).”

Diante desses fatores, cabe ao professor buscar fontes de pesquisas alternativas que expliquem como trabalhar Astronomia junto a alunos com deficiência.

Este trabalho tem como objetivo elaborar um levantamento bibliográfico com base nas atas ou anais de seis congressos relacionados à área de Ensino de Ciências no Brasil. Busca-se em específico, estabelecer um panorama dos trabalhos publicados nesses congressos, que possuem abrangência nacional, envolvendo o Ensino de Astronomia para pessoas com deficiência visual.

Como a inclusão de alunos com deficiência nas escolas já está inserido na Lei $\mathrm{N}^{0} 13.146$, de 6 de julho de 2015 (Brasil, 2015), e o Ensino de Astronomia está presente nos documentos oficiais como os PCN, um estudo sobre as publicações envolvendo essa temática será muito importante e poderá auxiliar professores e educadores do Ensino de Astronomia/Ciência, fornecendo-lhes um bom material para consulta e pesquisa.

O trabalho foi desenvolvido com características de pesquisa qualitativa, a partir da análise documental das atas ou anais dos congressos pesquisados (Estrela, 2018, Pereira, 2018, Ludke, \& Andre, 2013).

\subsection{Um breve histórico sobre a Educação para cegos}

A primeira escola para cegos foi fundada em Paris, em 1784, por Valentin Haüy (1745-1822). Louis Braille (18091852), um de seus discípulos, criou um sistema de leitura tátil. Com o surgimento do Sistema $B^{2}$ aille $^{2}$, várias escolas para cegos surgiram na Europa, assim como nos Estados Unidos. Como exemplo cita-se a Perkins School, onde Helen Keller, cega e muda desde os 19 meses de idade, conseguiu a façanha de uma graduação no Ensino Superior. A partir daí, os livros em Braille proliferaram-se pelo mundo. A própria United Nations Educational, Scientific and Cultural Organization (UNESCO) ou Organização das Nações Unidas para Educação, Ciência e Cultura, se esforçou para a unificação do Sistema Braille. No Brasil, a primeira escola voltada para cegos foi o Imperial Instituto dos Meninos Cegos, em 1854, no Rio de Janeiro, hoje conhecido com Instituto Benjamin Constant.

O ano de 1981 foi um marco para a luta dos direitos para as pessoas com deficiência, pois foi declarado pela Organização das Nações Unidas (ONU), como o Ano Internacional das Pessoas Portadoras de Deficiência. De acordo com Rogalski (2010), a Declaração de Salamanca (UNESCO, 1994), a aprovação da constituição de 1988 e a promulgação da LDB 9.394/1996 (Lei de Diretrizes e Bases da Educação Brasileira), (Brasil, 1996), fizeram com que a educação inclusiva começasse a ganhar força em solo brasileiro.

Segundo Mello e Machado (2017):

a partir da década de 1990, houve uma avalanche de leis, tanto no âmbito internacional quanto nacional, e uma mobilização por parte da sociedade civil organizada que passou a reivindicar direitos que modificaram de forma contundente o processo de acesso, permanência e atendimento ao deficiente visual e aos demais deficientes (Mello \& Machado, 2017, p. 37).

De acordo com Valentini et al. (2019), no Censo Escolar de 2013, haviam 80.415 estudantes com deficiência visual matriculados na Educação Básica no Brasil (Brasil, 2014). O autor afirma ainda que no cotidiano das instituições de Ensino Básico, ainda são perceptíveis o desconhecimento, os mitos e as dificuldades dos professores em lidar com os estudantes com deficiência visual.

É notório que apesar das mudanças nas legislações e nos documentos oficiais que norteiam o Ensino de Ciências para deficientes visuais, ainda são observadas dificuldades no processo de escolarização desses discentes (Ferreira, 2007).

\footnotetext{
${ }^{2}$ Sistema Braille: Sistema de escrita tátil em alto relevo utilizada por pessoas cegas ou com baixa visão.
} 


\subsection{Referencial de Pesquisa e Análise de Dados}

A área de Ensino de Astronomia/Ciência para deficientes visuais está em expansão no Brasil (Nepomuceno \& Zander, 2015), porém, mesmo com essa expansão, os professores vêm tendo bastante dificuldade para trabalhar essa temática com esses estudantes na sala de aula.

De forma a contribuir com o Ensino de Astronomia/Ciência para estudantes deficientes visuais, uma pesquisa qualitativa (Estrela, 2018, Pereira, 2018, Ludke, \& Andre, 2013), tipo levantamento bibliográfico foi realizada junto as atas ou anais de seis congressos da área de Ensino/Educação, no período entre 2001 e 2019.

Para Galvão (2010):

realizar um levantamento bibliográfico é se potencializar intelectualmente com o conhecimento coletivo, para se ir além. É munir-se com condições cognitivas melhores, a fim de: evitar a duplicação de pesquisas, ou quando for de interesse, reaproveitar e replicar pesquisas em diferentes escalas e contextos; observar possíveis falhas nos estudos realizados; conhecer os recursos necessários para a construção de um estudo com características específicas; desenvolver estudos que cubram lacunas na literatura trazendo real contribuição para a área de conhecimento; propor temas, problemas, hipóteses e metodologias inovadoras de pesquisa; otimizar recursos disponíveis em prol da sociedade, do campo científico, das instituições e dos governos que subsidiam a Ciência (Galvão, 2010, p. 6).

Os congressos analisados foram: o Simpósio Nacional de Educação em Astronomia (SNEA), Simpósio Nacional de Ensino de Física (SNEF), Encontro de Pesquisa em Ensino de Física (EPEF), Encontro Nacional de Pesquisa em Educação em Ciências (ENPEC), Congresso Nacional de Ensino de Ciências e Formação de Professores (CECIFOP) e o Simpósio Nacional de Ensino de Ciência e Tecnologia (SINECT). A escolha desses congressos é justificada pois todos são vinculados a área de Ensino de Ciência e Educação. Esses congressos são organizados com uma frequência bianual, ou seja, ocorrem de dois em dois anos, alguns em anos pares outros em anos ímpares. Escolheu-se este período entre 2001 e 2019 com o objetivo de uma obtenção maior de dados, podendo assim estabelecer um panorama mais real da produção desses congressos com relação a esse tema, ou seja, trabalhos que discutem o Ensino de Astronomia/Ciência para deficientes visuais.

Para análise dos artigos selecionados utilizou-se as técnicas de categorização, baseadas na teoria da análise de conteúdo (Bardin, 2000), bastante empregadas em estudos qualitativos. De acordo com a autora, a categorização é um modelo de técnicas de classificação de elementos constitutivos de um conjunto, por diferenciação e, seguidamente, por reagrupamento segundo o gênero, com critérios previamente definidos. A busca dos artigos para análise na pesquisa foi realizada por meio da leitura inicial do título, resumo e palavras-chave.

Em relação à pesquisa bibliográfica, Bretones e Megid Neto (2006) afirmam que:

estudos de descrição e análise da produção acadêmica em determinado campo é comumente denominado "pesquisas do estado da arte". Esse tipo de pesquisa permite conhecer melhor a produção, identificando suas principais tendências e resultados além de contribuir para uma divulgação mais adequada desses conhecimentos, bem como indicar novas possibilidades de pesquisa, propiciando avanços na área (Bretones \& Megid Neto, 2006, p.1).

\section{Metodologia}

Esta pesquisa realizou-se a partir das seguintes etapas:

- Levantamento numérico de todos os artigos relacionados à Astronomia nos congressos citados e apresentados no Quadro 1;

- Escolha dos artigos que relacionam o Ensino de Astronomia para pessoas com deficiência visual;

- Categorização dos artigos vinculados à Astronomia e deficientes visuais a partir de três descritores pré-determinados.

Alguns dados dos congressos pesquisados estão apresentados no Quadro 1. 
Quadro 1: Dados quantitativos dos congressos de 2001 a 2019

\begin{tabular}{|c|c|c|c|c|}
\hline Congresso & Período & $\begin{array}{c}\text { Número de } \\
\text { Edições }\end{array}$ & $\begin{array}{c}\text { Número de publicações } \\
\text { relacionadas à } \\
\text { Astronomia }\end{array}$ & $\begin{array}{c}\text { Número de } \\
\text { Publicações } \\
\text { relacionadas à } \\
\text { Astronomia para } \\
\text { deficientes visuais }\end{array}$ \\
\hline CECIFOP & 2017 a 2019 & 2 & 2 & 0 \\
\hline ENPEC & 2011 a 2019 & 5 & 107 & 3 \\
\hline EPEF & 2002 a 2018 & 9 & 38 & 1 \\
\hline SINECT & 2009 a 2018 & 6 & 10 & 0 \\
\hline SNEA & 2011 a 2018 & 6 & 513 & 7 \\
\hline SNEF & 2001 a 2019 & 10 & 265 & $\mathbf{2 3}$ \\
\hline Total & $\mathbf{2 0 0 1}$ a 2019 & $\mathbf{3 8}$ & $\mathbf{9 3 5}$ & \\
\hline
\end{tabular}

Fonte: Dados da Pesquisa.

Observa-se que os congressos que ocorrem em anos pares são: EPEF, SINECT e SNEA, sendo que esses dois últimos congressos tiveram suas primeiras edições em anos ímpares (SINECT 2009 e SNEA 2011), Quadro 1. Os congressos CECIFOP, ENPEC e o SNEF tradicionalmente ocorrem em anos ímpares.

Observou-se que de um total de 935 artigos publicados com temática vinculada à Astronomia, apenas 23 (cerca de 2,5\%) abordaram a inclusão de alunos com deficiência visual.

Foi observado ainda entre os congressos destacados no Quadro 1, que o SNEA é o evento com o maior número de publicações sobre o tema Astronomia e o segundo maior nas publicações sobre Astronomia envolvendo cegos ou pessoas com deficiência visual. Isso pode ser justificado pelo fato de o SNEA ser um congresso voltado especificamente para o Ensino de Astronomia, havendo um grande número de publicações disponibilizadas em suas atas ou anais.

Notou-se, também, que o CECIFOP e o SINECT não apresentaram nenhum trabalho envolvendo Astronomia para pessoas com deficiência visual. No CECIFOP, isso pode ter se dado pelo fato de ser um congresso ainda novo, sendo que só houveram duas edições até 2019, sendo a primeira ainda em 2017. No SINECT, um dos motivos para isso ter ocorrido pode ser o fato de ele ser um congresso voltado para Ciência e Tecnologia, e aparatos, mecanismos tecnológicos e até mesmo softwares destinados ao Ensino de Astronomia para pessoas com deficiência visual não são comumente encontrados em periódicos da área de Ensino de Ciências.

O Quadro 2, apresenta os títulos dos artigos selecionados que relacionam Astronomia e deficiência visual, assim como a sigla do congresso e o ano em que ele ocorreu. 
Quadro 2: Artigos selecionados nos congressos.

\begin{tabular}{|c|c|c|}
\hline Título & Congresso & Ano \\
\hline 1 - Explicando o fenômeno da sombra para alunos com deficiência visual & SNEF & 2011 \\
\hline $\begin{array}{l}2 \text { - Modelo experimental para o Ensino das Fases da Lua aos indivíduos } \\
\text { com e sem deficiência visual }\end{array}$ & SNEF & 2011 \\
\hline $\begin{array}{l}3 \text { - Um estudo exploratório de pesquisas brasileiras sobre Educação em } \\
\text { Astronomia para deficientes visuais }\end{array}$ & SNEF & 2011 \\
\hline $\begin{array}{l}4 \text { - Uma abordagem do Efeito Doppler para alunos com deficiência } \\
\text { visual }\end{array}$ & SNEF & 2015 \\
\hline $\begin{array}{l}5 \text { - Construção de maquetes no contexto da deficiência visual: } \\
\text { possibilidade para o ensino de temas de Astronomia no Ensino } \\
\text { Fundamental Dois }\end{array}$ & SNEF & 2017 \\
\hline $\begin{array}{l}6 \text { - O Ensino de Astronomia no contexto da deficiência visual: um } \\
\text { panorama sobre pesquisas e propostas desenvolvidas para a prática } \\
\text { inclusiva }\end{array}$ & SNEF & 2017 \\
\hline 7 - Explorando a Lua em uma escola inclusiva & SNEF & 2017 \\
\hline $\begin{array}{l}8 \text { - O ensino de alguns fenômenos astronômicos em uma escola de } \\
\text { inclusão }\end{array}$ & SNEF & 2017 \\
\hline $\begin{array}{l}9 \text { - O Ensino de Astronomia e a deficiência visual: desafios e } \\
\text { possibilidades enfrentados para a pesquisa }\end{array}$ & SNEF & 2019 \\
\hline $\begin{array}{l}10 \text { - Ensinando Astronomia para um aluno com múltipla deficiência: uma } \\
\text { proposta de inclusão e Ensino de Física }\end{array}$ & SNEF & 2019 \\
\hline $\begin{array}{l}11 \text { - "Ei moça, qual peso da laranja?" percepção tátil da força peso em } \\
\text { diferentes planetas do Sistema Solar }\end{array}$ & SNEF & 2019 \\
\hline $\begin{array}{l}12 \text { - O Ensino de Astronomia para alunos cegos e a inclusão nos espaços } \\
\text { não formais }\end{array}$ & SNEF & 2019 \\
\hline 13 - Astronomia com arte: estratégias para o ensino a deficientes visuais & SNEA & 2011 \\
\hline $\begin{array}{l}14 \text { - Contribuições de Vygotsky no Ensino de Astronomia para } \\
\text { deficientes visuais }\end{array}$ & SNEA & 2011 \\
\hline $\begin{array}{l}15 \text { - Estratégias não formais de Ensino de Astronomia para deficientes } \\
\text { visuais }\end{array}$ & SNEA & 2011 \\
\hline $\begin{array}{l}16 \text { - Elaboração de material para Ensino de Astronomia para deficientes } \\
\text { visuais: o caso das supernovas }\end{array}$ & SNEA & 2014 \\
\hline 17 - As fases da Lua: experiência com deficientes visuais & SNEA & 2014 \\
\hline $\begin{array}{l}18 \text { - A produção bibliográfica sobre uso de modelos didáticos para o } \\
\text { Ensino de Astronomia com deficientes visuais }\end{array}$ & SNEA & 2014 \\
\hline 19 - Modelo de fases da Lua para deficientes visuais & SNEA & 2018 \\
\hline $\begin{array}{l}20 \text { - Ouvir e sentir estrelas: Astronomia para pessoas com deficiência } \\
\text { visual }\end{array}$ & EPEF & 2018 \\
\hline $\begin{array}{l}21 \text { - Uma proposta para abordagem das Leis de Kepler em sala de aula de } \\
\text { alunos com deficiência visual }\end{array}$ & ENPEC & 2009 \\
\hline $\begin{array}{l}22 \text { - A elaboração de recursos didáticos para o Ensino de Astronomia } \\
\text { para deficientes visuais }\end{array}$ & ENPEC & 2017 \\
\hline $\begin{array}{l}23 \text { - Concepções das pessoas com deficiência visual sobre a Lua para } \\
\text { produção de um material paradidático adaptado. }\end{array}$ & ENPEC & 2017 \\
\hline
\end{tabular}

Fonte: Dados da Pesquisa.

Após a leitura dos 23 artigos relacionados no Quadro 2, utilizou-se os descritores apresentados no Quadro 3 como recurso de pesquisa qualitativa para análise das principais características desses artigos. 
Quadro 3: Descritores para análise dos artigos.

\begin{tabular}{|c|l|l|}
\hline & \multicolumn{1}{|c|}{ Descritores para análise dos artigos } & \multicolumn{1}{c|}{ Objetivos do descritor } \\
\hline 1 & Nível de ensino para qual o artigo é voltado? & $\begin{array}{l}\text { Verificar se o artigo trabalha com Ensino } \\
\text { Básico ou Superior }\end{array}$ \\
\hline 2 & $\begin{array}{l}\text { O artigo envolve uso de softwares ou recursos } \\
\text { táteis? }\end{array}$ & $\begin{array}{l}\text { Verificar quais são os softwares ou demais } \\
\text { recursos utilizados }\end{array}$ \\
\hline 3 & $\begin{array}{l}\text { A qual conteúdo relacionado à Astronomia se refere } \\
\text { o artigo? }\end{array}$ & $\begin{array}{l}\text { Verificar se há algum tema de Astronomia } \\
\text { que predomine entre os artigos }\end{array}$ \\
\hline
\end{tabular}

Fonte: Dados da Pesquisa.

\section{Resultados e Discussão}

Com base na análise realizada junto aos artigos, tendo como referência os descritores do Quadro 3, apresenta-se a seguir uma análise qualitativa dos dados, acompanhada em alguns casos, da sua respectiva representação em gráficos. A Figura 1 mostra os resultados obtidos com relação ao descritor 1, (Quadro 3).

Observa-se que dez artigos estão relacionados ao Ensino Básico (Ensino Fundamental e Ensino Médio) e nenhum artigo entre os selecionados, se relaciona ao Ensino Superior. Pode-se supor que a maior produção de trabalhos junto ao Ensino Básico se dá principalmente pela inserção dos alunos deficientes visuais nas escolas de Ensino Regular, dada pela Lei $\mathrm{N}^{0}$ 13.146, de 6 de julho de 2015 (Brasil, 2015). Essa falta de trabalhos envolvendo o acesso de alunos deficientes visuais ao Ensino Superior, tendo contato com a temática Astronomia, retrata também que o acesso desses alunos a Astronomia/Ciência nesse nível de ensino ainda é pequeno. Vários cursos de graduação nas áreas de Ciências (Biologia, Física e Química) não apresentam em suas matrizes curriculares disciplinas que promovam uma formação específica em Astronomia (Paganotti, 2020).

A maioria dos trabalhos (Quadro 2), 13 especificamente, não foram voltados apenas para uma modalidade de ensino, mas sim para outras modalidades como o ensino não formal, ou seja, realizado em espaços fora da escola como museus e planetários. O ensino informal apresenta a vantagem de envolver qualquer nível de ensino, desde o básico até a educação especial de jovens e adultos (EJA) ou o Ensino Superior.

Figura 1: Descritor 1.

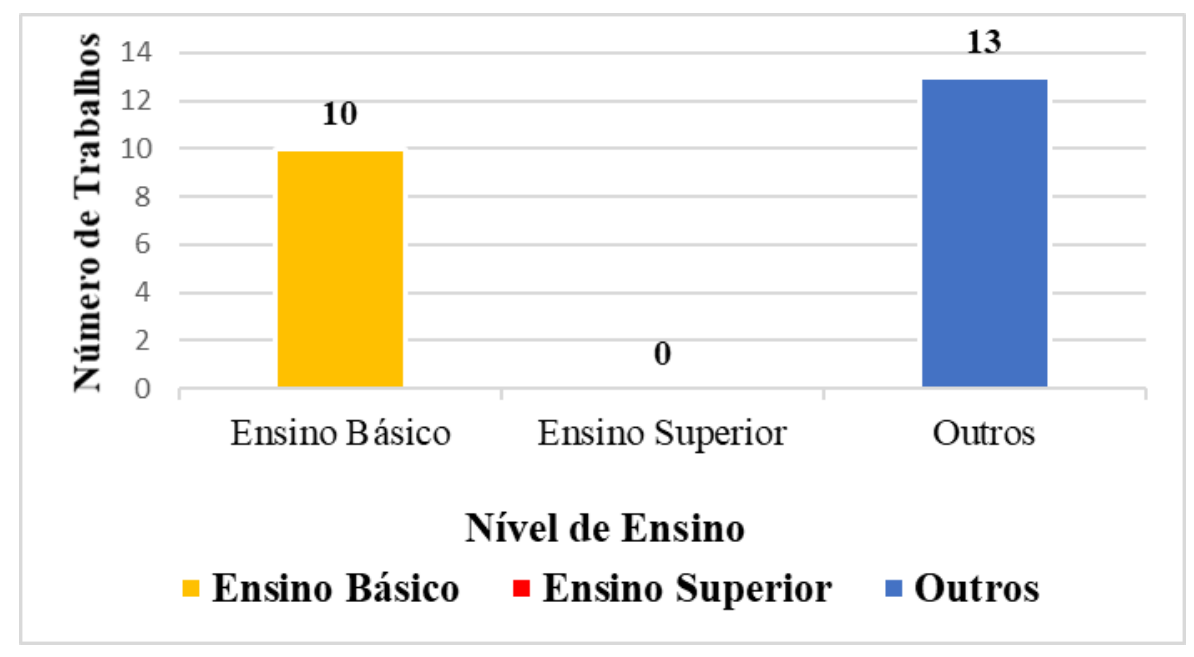

Fonte: Dados da Pesquisa.

O descritor 2 (Quadro 3) busca informações sobre o uso de softwares ou recursos táteis para o Ensino de Astronomia junto aos alunos deficientes visuais. A Figura 2 apresenta os dados obtidos com a análise dos artigos com base nesse descritor. 
Figura 2: Descritor 2.

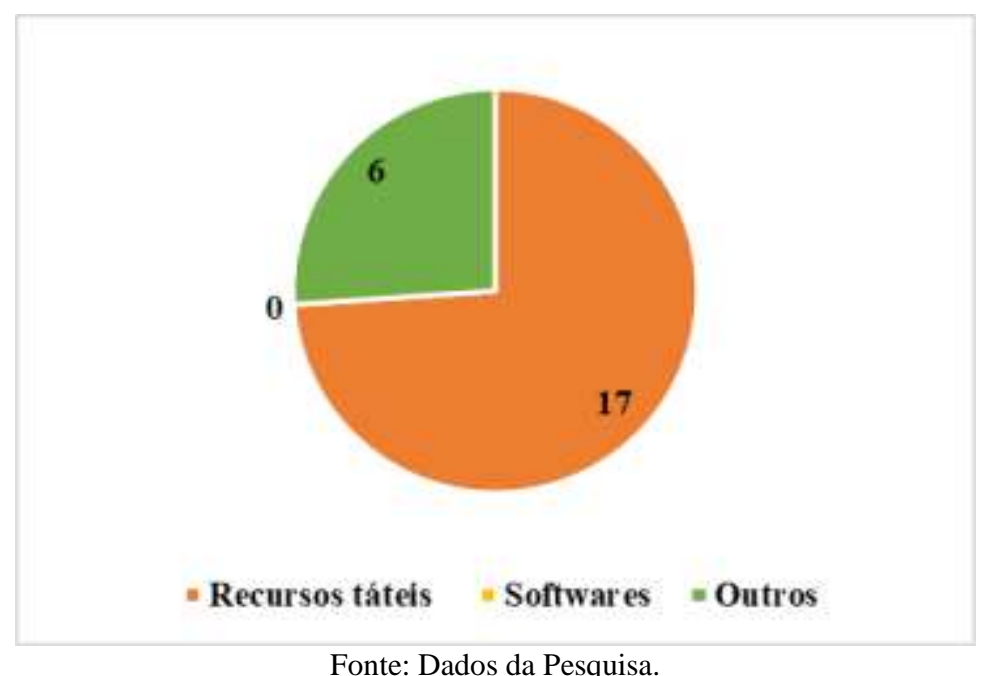

Fonte: Dados da Pesquisa.

Ao observar a Figura 2, é fácil notar que a grande maioria dos trabalhos tratam do uso de recursos táteis para o Ensino de Astronomia para pessoas com deficiência visual, visto que, o uso do tato é uma ótima forma de as pessoas com essa deficiência se inteirarem do que está acontecendo. Inclusive, um dos sistemas mais utilizados por pessoas com deficiência visual é o Sistema Braille.

Um dado preocupante é que do total de trabalhos analisados nenhum tratou especificamente do uso de softwares como recurso que pode auxiliar o aprendizado de Astronomia pelos estudantes deficientes visuais. Como atualmente a sociedade está bastante inserida no uso de tecnologias digitais, é de suma importância que sejam feitas mais pesquisas e atividades, discutindo, incentivando e envolvendo a aplicação desses recursos para a tarefa de ensinar Astronomia/Ciência aos alunos com deficiência visual.

Os outros trabalhos não tratam especificamente do uso de recursos táteis ou de softwares para o Ensino de Astronomia para pessoas com deficiência visual, mas sim de outros assuntos, em grande maioria, sobre pesquisa educacional como retratado por exemplo nos artigos 6, 13 e 18 do Quadro 2.

O descritor 3 (Quadro 3) investiga os temas de Astronomia abordados entre os artigos selecionados e verifica se há um parâmetro ou um tema mais recorrente entre os trabalhos. Os resultados obtidos para esse descritor estão apresentados na Figura 3. 
Figura 3: Descritor 3.

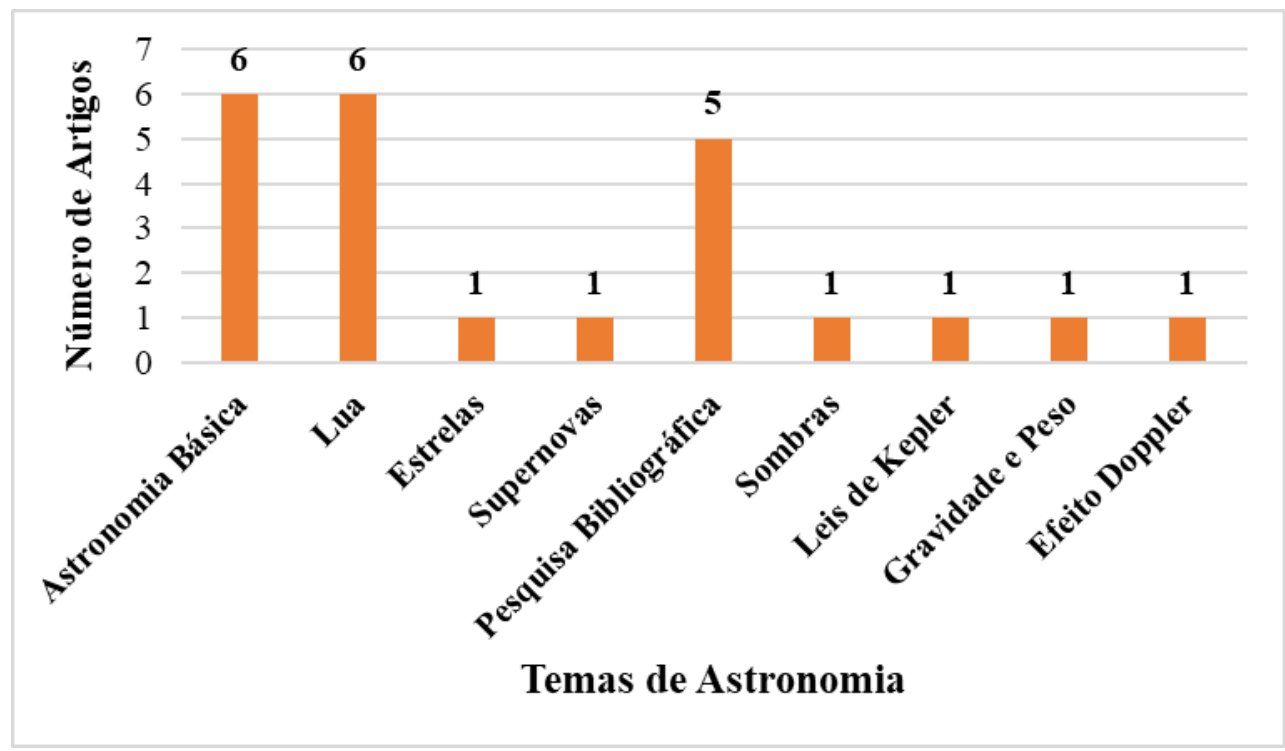

Fonte: Dados da Pesquisa.

Observa-se que os assuntos mais predominantes relacionados a Astronomia são Lua e Astronomia Básica. Este último não envolve um assunto específico, mas vários assuntos, como estações do ano, o Sistema Solar, planetas e eclipses.

Justifica-se a predominância desses temas visto que são conteúdos presentes no dia a dia dos alunos e da população em geral pois estão sempre sendo noticiados pela mídia televisiva e presentes nas redes sociais, principalmente em grupos ou canais que trabalham ou discutem a temática Astronomia.

Foi uma surpresa perceber na Figura 3 que temas como Leis de Kepler, Gravidade e peso foram citados cada um em apenas um artigo. Esperava-se uma presença maior desses temas nos trabalhos investigados visto que os mesmos estão presentes no currículo escolar de Física do Ensino Médio, como sugere os documentos oficiais para esse nível de ensino, os Parâmetros Curriculares Nacionais (PCN) (Brasil, 2000) e a atual Base Nacional Comum Curricular (BNCC) (Brasil, 2017). Esses temas são inclusive abordados nos livros didáticos (Programa Nacional do Livro e do Material Didático - PNLD) de Física do Ensino Médio.

Tópicos como Supernovas e Efeito Doppler, por exemplo, são pouco abordados no Ensino Básico, o que pode explicar o baixo número de publicações sobre essas temáticas de Astronomia. Temas como estrelas e sombras, que são populares, também aparecem pouco entre os trabalhos pesquisados (Figura 3). No geral, observou-se uma variedade das temáticas de Astronomia abordadas nos artigos investigados, não havendo assim uma tendência para algum conteúdo específico de Astronomia.

\section{Conclusão}

Dada a importância da produção acadêmica que trabalha modelos e metodologias que possam facilitar o Ensino de Astronomia para deficientes visuais, esta pesquisa apresenta um conjunto desses trabalhos, provenientes dos anais ou atas dos principais simpósios, encontros ou congressos nacionais da área de Ensino de Astronomia/Ciência/Física do Brasil.

Ao analisar os dados obtidos com base nos descritores apresentados no Quadro 3, pode-se concluir com as publicações dos seis congressos e seus 935 artigos com temas vinculados à Astronomia (Quadro 1), que a produção acadêmica envolvendo o Ensino de Astronomia para alunos deficientes visuais ainda é muito baixa no Brasil, afinal, foram selecionados apenas 23 artigos específicos, envolvendo essa temática. 
Observou-se que o número de trabalhos relacionados à Astronomia e pessoas com deficiência visual aumentou consideravelmente na última década, como observado no Quadro 2, onde os 23 artigos selecionados foram provenientes de congressos entre 2009 e 2019. Pode-se atribuir isso ao fato de que a Lei Brasileira de Inclusão de Deficientes no Ensino Regular (Lei $\mathrm{N}^{0}$ 13.146) (Brasil, 2015) foi criada nesta década. Além disso, temas relacionados à inclusão e o Ensino de Astronomia utilizando recursos digitais vêm sendo cada vez mais debatidos, não só no ambiente escolar, como também em redes sociais e outros espaços de aprendizagem não-formais (Langhi \& Nardi, 2009; Dos Santos et al., 2019).

Com relação ao descritor 1 do Quadro 3, conclui-se que a preocupação dos autores dos artigos selecionados (Quadro 2) não é somente com um nível de ensino pré-determinado, mas sim com todas as áreas de ensino, englobando vários segmentos da sociedade, havendo produções vinculadas inclusive à educação informal. Observa-se que a divulgação científica em ambientes informais pode favorecer a disseminação dos conhecimentos científicos fora do ambiente escolar para pessoas com ou sem deficiência visual, contribuindo inclusive com o combate a mitos relacionados à Astronomia como por exemplo, as afirmações sobre "Terra plana ou a negação da ida do homem à Lua", as chamadas "fake News" ". A divulgação científica nas escolas e nos ambientes informais reforça a ideia de que a Astronomia não é uma Ciência voltada apenas para as pessoas videntes ${ }^{4}$, mas que está ao alcance de todos.

Com relação ao descritor 2 (Quadro 3), conclui-se que os artigos descrevem o uso predominante de recursos táteis para o Ensino de Astronomia para as pessoas com ou sem deficiência visual, pois é a metodologia mais fácil e prática na execução dessa tarefa. A pesquisa mostrou também a não utilização de softwares ou outros recursos digitais pelos pesquisadores e educadores, afinal, entre os 23 artigos selecionados, nenhum trabalhou o tema Astronomia junto a estudantes deficientes visuais utilizando Tecnologias Digitais de Informação de Comunicação (TDIC). Como a sociedade atual está bastante imersa na utilização de recursos tecnológicos digitais, é desejável a utilização desses recursos na educação, seja no modo formal ou informal, principalmente dada a importância de se estabelecer a Educação Inclusiva.

A partir da análise dos resultados obtidos com o descritor 3 (Quadro 3), concluiu-se que, apesar de haver um maior número de trabalhos sobre o tema Lua ou tópicos relacionados a Astronomia Básica, os conteúdos que vem sendo relatados nas pesquisas, em sala de aula ou fora dela são bem variados, e dessa forma, contribuem para a divulgação científica dos conceitos de Astronomia/Ciência.

Há espaço para a elaboração de trabalhos futuros, explorando o desenvolvimento dessa temática em repositórios de teses e dissertações, vislumbrando as tendências dessas publicações com relação ao Ensino de Astronomia/Ciência para discentes com algum tipo de deficiência.

Espera-se que este trabalho possa destacar junto aos leitores a necessidade de uma maior produção de trabalhos acadêmicos que tenham como foco o apoio e a atenção para o Ensino de Astronomia/Ciência às pessoas com deficiência visual. Destaca-se a necessidade e a preocupação em melhorar o acesso dos estudantes deficientes visuais ao Ensino de Astronomia/Ciência a partir do desenvolvimento de novas metodologias de ensino que permitam não somente o aprendizado desses conteúdos, mas também e principalmente a verdadeira inclusão desses discentes no cotidiano escolar, permitindo assim que a lei de inclusão de alunos com deficiência (Lei $\mathrm{N}^{0}$ 13.146) (Brasil, 2015) realmente seja cumprida nas escolas de todo o Brasil.

\section{Referências}

Bardin, L. (2000). A análise de conteúdo (3a ed.). Edições 70.

Brasil. Parâmetros Curriculares Nacionais. Bases Legais. Brasília, MEC. (2000). <http://portal.mec.gov.br/seb/arquivos/pdf/blegais.pdf>.

\footnotetext{
${ }^{3}$ Notícias falsas e boatos que são divulgadas pelos meios de comunicação.

${ }^{4}$ Pessoas que enxergam; sem deficiência visual.
} 
Brasil. Ministério da Educação. PCN + Ensino Médio: Orientações Educacionais Complementares aos Parâmetros Curriculares Nacionais. (2007). de $\langle$ http://portal.mec.gov.br/seb/arquivos/pdf/CienciasNatureza.pdf >.

Brasil. Ministério da Educação. Diretoria de Políticas de Educação Especial. (2014). Principais Indicadores da Educação de Pessoas com Deficiência. Brasília: MEC/INEP. <http://portal.mec.gov.br/index.php?option=com_docman\&view=download\&alias=16759prin-indicadores-da-educacao-de-pessoascom-deficiencia\&Itemid=30192>.

Brasil. Lei n. 13.146, de 6 de julho de 2015 (2015). Destinada a assegurar e a promover, em condições de igualdade, o exercício dos direitos e das liberdades fundamentais por pessoa com deficiência, visando à sua inclusão social e cidadania. Brasília, DF. <http://www.planalto.gov.br/ccivil_03/_ato20152018/2015/lei//13146.htm>

Brasil. Ministério da Educação. Base Nacional Comum Curricular. (2017).

Bretones, P. S., \& Megid, N. J. (2006). A Educação em Astronomia nos trabalhos das reuniões anuais da Sociedade Astronômica Brasileira. Boletim da Sociedade Astronômica Brasileira, 26(2), 55-72.

Dos Santos, H. L., Lucas, L. B., Sanzovo, D. T., \& Pimentel, R. G. (2019). O uso das tecnologias para o Ensino de Astronomia: uma revisão sistemática de literatura. Res., Soc. Dev, 8 (4), e2284812.

Estrela, C. (2018). Metodologia Científica: Ciência, Ensino, Pesquisa. Editora Artes Médicas.

Fares, E. A., Martins, K. P., Araujo, L. M., \& Filho, M. S. (2004). O universo das sociedades numa perspectiva relativa: exercícios de etnoastronomia. Revista Latino-Americana de Educação em Astronomia, (1), 77-85.

Faria, R. Z., \& Voelzke, M. R. (2008). Análise das características da aprendizagem de Astronomia no Ensino Médio nos municípios de Rio Grande da Serra, Ribeirão Pires e Mauá. Revista Brasileira de Ensino de Física, 30 (4), 4402.

Ferreira, M. E. C. (2007). O enigma da inclusão: das intenções às práticas pedagógicas. Rev. Educação e Pesquisa, 33(3), 543-560.

Galvão, M. C. B. (2010). O levantamento bibliográfico e a pesquisa científica. In L. J. Franco, \& A. D. C. Passos (Orgs.), Fundamentos de epidemiologia (2a ed.). http://www2.eerp.usp.br/Nepien/DisponibilizarArquivos/Levantamento_bibliograficoCristianeGalv.pdf.

Langhi, R., \& Nardi, R. (2009). Ensino da Astronomia no Brasil: educação formal, informal, não formal e divulgação científica. Revista Brasileira de Ensino de Fisica, 31 (4), 4402.

Longhini, M. D. (2009). Será o Cruzeiro do Sul uma cruz? Rev. Física na Escola, 10(1).

Mello, H., \& Machado, S. (2017, maio). A formação histórica da educação para cegos no Brasil: uma análise contextualizada das leis do Império à República. Anais do Seminário Luso-Brasileiro de Educação Inclusiva: o ensino e a aprendizagem em discussão, (1).

Ludke, M., \& Andre, M. E. D. A. (2013). Pesquisas em educação: uma abordagem qualitativa. E.P.U.

Nepomuceno, T. A. R., \& Zander, L. D. (2015). Uma análise dos recursos didáticos táteis adaptados ao ensino de ciências a alunos com deficiência visual inseridos no ensino fundamental. Revista do Instituto Benjamin Constant, 1(58), 49-63.

Oliveira, E. F., Voelzke, M. R., \& Amaral, L. H. (2007). Percepção astronômica de um grupo de alunos do ensino médio da rede estadual de São Paulo da cidade de Suzano. Revista Latino-Americana de Educação em Astronomia, 4(1), 79- 99.

Paganotti, A. (2020). Características do Ensino de Astronomia nos cursos de Licenciatura em Física dos Institutos Federais de Educação Ciência e Tecnologia. 170 f. Tese (Doutorado em Ensino de Ciências e Matemática) - Universidade Cruzeiro do Sul, São Paulo.

Pereira A. S., Shitsuka, D. M., Parreira, F. J., Shitsuka, R. (2018). Metodologia da pesquisa científica. [free e-book]. Santa Maria/RS. Ed. UAB/NTE/UFSM.

Rogalski, S. M. (2010). Histórico do surgimento da Educação Especial. Revista de Educação do IDEAU, 5(12).

Romero, R., \& Sousa, S. (2008, setembro). Educação Inclusiva: alguns marcos históricos que produziram a educação atual. Anais do Congresso de Educação - EDUCERE, Curitiba, PR, Brasil, (8).

Soler, D. R., \& Leite, C. (2012). A importância e justificativas para o ensino de Astronomia: um olhar para as pesquisas da área. In: II SIMPÓSIO NACIONAL DE EDUCAÇÃO EM ASTRONOMIA. Anais do II Simpósio Nacional de Educação em Astronomia. São Paulo, 2012. <https://www.sabastro.org.br/wp-content/uploads/2017/03/SNEA2012_TCO21.pdf $\geq$.

UNESCO. Declaração de Salamanca e Linha de Ação Sobre Necessidades Educativas Especiais. Brasília: Coordenadoria Nacional para Integração da Pessoa Portadora de Deficiência, 1994. http://portal.mec.gov.br/seesp/arquivos/pdf/salamanca.pdf.

Valentini, C. B., Bisol, C. A., Paim, L. S., \& Ehlers, A. P. F. (2019). Educação e deficiência visual: uma revisão de literatura. Rev. Educ. Especial. 32 , 1 - 20. <https://periodicos.ufsm.br/educacaoespecial/article/view/33154>. 